\title{
INTERNAL CONTROL SYSTEM PROBLEMS, CHALLENGES AND ISSUES OF ITS IMPROVEMENT
}

\section{DALI SOLOGHASHVILI}

Academic Doctor of Economics, Professor

Akaki Tsereteli State University, Georgia

dali.sologhashvili-udesiani@arsu.edu.ge

\section{TATIA UDESIANI}

\section{PhD Student}

Caucasus International University, Georgia

tata.udesiani@gmail.com

\begin{abstract}
The activities of the budget institution are directly related to the society and each successful step is aimed at the development of the country. An effective system of internal control is the main lever for managing and minimizing the risks in budgetary institutions. That is why the study and elimination of problems and shortcomings related to internal control will functionally strengthen this system, which will have a positive impact on the efficiency of the functioning of budgetary institutions. The results of the research work and the recommendations developed based on it, will help budget institutions to improve the internal control system and, consequently, to manage risks.

Resources in the public sector are created based on public money and therefore should be used in the public interest. That is why it is very important in the public sector to control the acquisition, use and protect the existing resources, which is regulated by the internal control system.

The article deals with the issues of an effective internal control system and its quality assurance in Georgia. The paper discusses the importance of the internal control system and its components, the role, and importance of quality assurance of the internal control system about the identified problematic issues. The role and benefits of internal audit as an integral part of the internal control system are evaluated and analyzed on the example of the Georgian budget institution.

Based on the conducted research and analysis, relevant conclusions have been made and problematic issues related to the internal control systems in the budget sector of Georgia have been assessed.
\end{abstract}

\section{KEYWORDS: INTERNAL CONTROL, INTERNAL AUDIT, BUDGETARY INSTITUTIONS, QUALITY ASSURANCE, EFFICIENCY.}

For citation: Sologhashvili, D., Udesiani, T., (2021). Internal Control System Problems, Challenges and Issues of its Improvement. Globalization and Business. 12, 166-172. https://doi.org/10.35945/gb.2021.12.023

\section{INTRODUCTION}

The internal control system in public institutions is one of the main levers for managing existing risks and minimizing it. Lack of internal control in budgetary institutions, complete or partial disruption, poses certain risks to the transparency and accountability of budget expenditures.

Having a comprehensive internal control mechanism is especially important for a developing country like Georgia.

Although the establishment and development of an internal control system in Georgia is not a small amount of time, there are still problematic issues that require finding and improving solutions. The existence of problematic issues is also because budgetary institutions are characterized by risks such as improper, uneconomical, unproductive management of budget funds, corruption, misappropriation, and others (Udesiani, 2015). At the same time, there is a high public interest in Georgia regarding the ongoing processes in budgetary institutions and the rational management of budgetary funds.

An effective system of internal control is the main lever for managing and minimizing the risks in the country's budgetary institutions. Therefore, the study and elimination of problems and shortcomings related to internal control will functionally strengthen this system.

The financial management reform in Georgia began in 2007, when a financing agreement was signed between the Government of Georgia and the European Commission to support Georgia's financial management reform (Gongadze, 2012). These were the first steps in establishing an internal financial control system in our country and, consequently, in introducing an internal control system. Later, the adequacy 
of the state internal financial control system became a kind of indicator to assess the effective functioning of the public institution (2018 Consolidated Annual Report ..., 2019).

Initially, there were three main conditions for the institutional development of state internal financial control: the establishment of an appropriate legal framework, internal audit entities, and a harmonization center.

In 2009, the Ministry of Finance of Georgia developed a strategic document "On Public Sector Financial Management Reform" (2009-2013), according to which it was planned to establish and develop an internal control system in the public sector. This strategic document included a five-year plan and measures for the establishment of internal control mechanisms in the country, based on the concept developed by the European Union on Public Internal Financial Control (PIFC) and the guidelines and standards of the International Organization of Supreme Audit Institutions (INTOSAI) for the public sector. In addition, a draft law on State Internal Audit and Inspection was drafted in June 2009, which was later approved by the Parliament of Georgia in March 2010.

The law provided for the establishment of internal audit entities in the Ministries of Georgia, the Ministries of the Autonomous Republics, local self-government executive bodies - boards (city halls) and legal entities under public law. It regulated the functioning of each such entity, the rights and duties, the principles of responsibility and independence. Currently, the same issues are regulated by the Law of Georgia on State Internal Financial Control ((Law of Georgia on State..., 2010).

In parallel with the introduction of the internal control system, the Georgian legislation was improved and underwent a number of changes. Relevant legislative acts were developed in stages and Action Plan for the Development of the State Internal Financial Control System and others.

Within the framework of the above-mentioned reform, internal audit entities were gradually established in the budgetary institutions of Georgia, which are an integral part of "monitoring" according to the coso model (internal control framework form) and which play an important role in promoting the implementation of internal control. It is an independent, objective, the persuasive and consulting activity aimed at improving the activity, ensuring the achievement of its goals, and the complete fulfillment of its tasks. It evaluates and improves the effectiveness of risk management, control, and governance processes with a systematic, disciplined and organized approach.

Subject and object of research. The subject of research is the assessment and analysis of the quality of control mechanisms in budgetary institutions. The object of research is internal control systems and their effectiveness in budgetary institutions.

Research Methodology and Methods. The methodological basis of the research is International Standards on Auditing (ISA), standards of the International Organization of Supreme Audit Institutions (INTOSAI), international and locally developed methodologies, manuals and instructions, legislative and normative documents, researches and works of Georgian and foreign scientists, results of research and audits conducted by various non-governmental or governmental bodies, reports and other public information developed by relevant organizations.

\section{Research analysis}

We started the analysis of the internal control system in the budgetary institutions of Georgia by studying the provisions of the Internal Audit Department of the same institutions, as the internal audit is an integral part of the internal financial control system and at the same time, great resources are spent for its introduction and development. In the first stage, we took several ministries. Since the Ministry of Finance of Georgia facilitates and ensures the introduction, development, and functional improvement of the state internal financial control system in the institutions and the coordination of these issues, we considered it expedient to first evaluate the statute of this Ministry.

The Statute of the Internal Audit Department of the Ministry of Finance of Georgia was approved on October 22, 2010 by Order N801 of the Minister of Finance. It was established on the basis of the Law of Georgia on State Internal Audit and Inspection in force at that time and its main goals and objectives were defined as:

1. Promoting the efficiency and effectiveness of the functioning and management procedures of the Ministry system (Order N801 of the Minister of Finance ..., 2010);

2. Examination of financial resources, material values, intangible assets of other property, use, management and protection of legality, purpose, expediency, economy, and efficiency, compliance with applicable law, as well as accounting and study of existing risk, accounting, and financial statements. Identify, evaluate the factors and develop appropriate strategies and recommendations for their management, the implementation of which will help the Ministry to achieve the set goals;

3. Responding to the law in connection with the facts of misconduct and preventing such misconduct.

The above-mentioned regulation also defined the structure of the department, which included the following structural units:

- Inspection Division;

- Monitoring and Internal Control Division;

- Risk Study Division.

The statute of the Internal Audit Department of the Ministry of Finance of Georgia has undergone 9 changes so far and the structure, functions and terms of the Department have been changed. Also, by the Laws of Georgia on Internal Financial Control and the Civil Service Law, the Regulation was periodically amended to comply with current legislation.

Currently, there are 2 divisions in the Internal Audit Department of the Ministry of Finance of Georgia - inspection and assurance services, which carry out their activities within the framework of their functions and duties.

The next ministry whose analysis of the regulations of 
the Internal Audit Department is the Ministry of Education, Science, Culture, and Sports of Georgia. His discussion is interesting in the sense that he was involved in the reform process from the very beginning and was introducing and introducing innovations in pilot mode, for example, such as information technology audit, system audit, efficiency audit.

The Statute of the Internal Audit Department of the Ministry of Education, Science, Culture and Sports of Georgia was approved by the Order N65 / N of the Minister of Education and Science of Georgia on August 4, 2010. This regulation was declared invalid on May 3, 2012 and the new regulation of the Internal Audit Department was approved by Order N89 / N. Last regulation was declared invalid on February 2, 2019 and the new regulation of the Internal Audit Department was approved by Order N11 / N.

According to the regulations approved in 2010, the main objectives of the Internal Audit Department are:

Improving the activities of the Ministry through the systematic, complex study of issues and risk management, control and evaluation of governance processes, improving financial management, promoting the legality of spending and using funds, other tangible assets, protecting the purposefulness and efficiency, producing legal procedures for the functioning and management of the Ministry. And elimination and prevention of functional defects;

Ensure that the Ministry monitors the strict implementation of the laws of Georgia, the decrees of the President of Georgia, the decrees of the Government of Georgia, the orders of the Prime Minister, and the legal acts of the Minister.

As the analysis showed, the statute of the Internal Audit Department of the Ministry of Education and Science underwent a fundamental change in 2012, changing the general statute, main tasks, functions, rules of internal audit, and more. The basis for this was the Law of Georgia on State Internal Financial Control (Order N89 / N of the Minister of Education ..., 2012).

For the current period, the Ministry of Education, Science, Culture and Sports of Georgia has three structural units - Internal Audit Division, Analytical Division, and Inspection Service. Each of them carries out activities within the framework of their function-duties. The Internal Audit Division (Order N11 / N of the Minister ..., 2019) conducts compliance, financial, systemic and performance audits, as well as monitoring, following approved strategic and annual plans. At the same time, it constantly raises the qualification of employees and introduces a form of self-assessment to ensure and improve quality.

To assess the issues related to the development of internal control throughout Georgia, we also analyzed the regulations of the municipalities, the City Hall internal audit services, and the changes made in it. As the analysis showed most of them were approved in 2014.

It is also interesting to note that in some cases the provision contains such records as:

- In carrying out the assigned tasks and functions, the Service is authorized within its competence to conduct internal audits/inspections. On the facts of actions (Resolution N11 of the City Council of Akhaltsikhe ...);
- Another example is when the Monitoring, Internal Control, and Inspection Department was established in the City Hall and, consequently, the rights and responsibilities were written together when the internal audit and inspection were functionally completely different. In one case, on January 12, 2018, the statute of the Internal Audit and Inspection Service was approved, according to which it was determined that the Service has one structural subdivision the Monitoring and Inspection Division. The main functions defined in this section are also important.

The main functions of the monitoring and inspection department are:

A) Develop recommendations to increase the economy, efficiency, and productivity of the City Hall;

B) Assessing/monitoring the compliance of the activities of the City Hall bodies with the legislation of Georgia due to the specifics; Monitoring compliance with the requirements of the legislation, analysis of expected violations and/or shortcomings and their prevention; Submit relevant recommendations to the Mayor;

C) Monitoring the further implementation of the recommendations developed and issued by the Service;

D) Cooperate with state bodies, public representatives, non-governmental organizations, and mass media within its competence.

Since, the effective functioning of internal audit as an important part of the internal financial control system is an important issue for achieving the set goals and objectives, we consider it expedient to properly define and develop their function in budgetary institutions, as internal audit For this, it is important for senior management to ensure the independence of internal audit, for which, first of all, internal audit should be separated from inspection. In addition, it is important for the internal audit to fulfill the requirements set by the legislation and standards and to fully perform its function - internal audit.

The analysis of the regulations showed the existence of problematic issues, so we considered it expedient to further evaluate the existing internal control systems in the municipalities. Because the municipalities were involved in the study only at the in-depth interview stage and due to the non-publicity of the information, the results of their activities could not be used (Measuring the Effectiveness of the Internal ..., 2016). Reports on audits conducted in 2014-2015 and 2016-2017, activity reports of the State Audit Office for 20162019 , as well as the results of audit audits of municipalities published in 2016-2020.

Across the country, the evaluation of the internal control system of municipalities reveals some thematic problematic issues that have a significant impact on the misuse and misappropriation of budget funds. For example;

- Violations in public procurement management:

Various violations were revealed in the public procurement management process due to the following reasons;

- Budget funds are transferred without complete documentary substantiation;

Unreasonably increased workloads and unit values. Unpaid work is remunerated; 
Weak control mechanisms are used in the process of planning and execution of work;

Changes in the timing of the work were made without proper justification, due to which the penalty sanctions provided by the contract were not applied;

The works specified in the contract are completely or partially unfulfilled.

It is also important to note that the current situation has not improved over the years. The results of the audits conducted in 2016-2017 reveal similar types of violations in the process of public procurement management, the total amount of which amounted to more than 33 million GEL.

The reason for this issue can be considered several factors, among which, in our opinion, one of the most important is the inefficiency of internal control in budgetary institutions. In the first stage, if we consider the issue in terms of the functioning of internal audit and take into account that these gaps are not found in internal audit reports, we can say that the functioning of internal audit in the organization is ineffective because it fails to achieve its goals and objectives (Report of the State Audit ..., 2015).

In particular:

1. Public procurement issues, especially when there are no effective and adequate control systems in the organization, are high-risk carriers. If the internal audit were to analyze the risk, then the public procurement process should be considered as one of the riskest processes, because it, in turn is associated with risks such as inappropriate, irrational and uneconomical spending of budget funds, restriction of competition, the possibility of legal dispute, financial loss. And so on.

2. If we consider the case that the public procurement processes were included in the audit, then the issue is different - given the above shortcomings, the internal audit was conducted without risk analysis.

It is important why we make such an assessment of this issue. The reasons are as follows:

- The audit of the public procurement process covers all issues from procurement planning to settlement. It is quite a complex process and is characterized (Udesiani, 2015) by many risky subprocesses. For example, the lack of procurement planning rules, which in turn is associated with inefficient planning, the risk of breaches of monetary limits, etc; Inefficient market research system, which in turn is associated with the risk of uneconomical and irrational spending of financial resources, etc.; Ineffective control system of contract execution, which is related to the risk of irrational and inappropriate spending of financial resources, etc. During the audit, each stage and issue is analyzed with relevant evidence. If the public procurement process were to be adequately studied (International Standards..., 2011) the settlement issues under the contracts would have to be addressed on an appropriate basis, which would have resulted in these issues being reflected in the audit report and relevant recommendations developed.
As for the unreasonably increased workloads and unit costs, this problem is also detected after the study/analysis of the grounds for changes to each contract. However, in addition to the significant problem of what is called inappropriate and irrational spending of budget funds, there is a problem related to internal control, which should also be addressed during the internal audit. An existing issue requires further study and a search for the reasons why things led to the existing one. As mentioned in previous chapters, the internal financial control system is not just an internal audit, an important role is played by the management. Accordingly, the analysis of the existing problem would make it possible to clearly identify the shortcomings that would be related to the weakness or non-existence of internal financial control. Another important issue that needs to be assessed during the internal audit is the risks of corruption and fraud, especially given the fact that unperformed work has been remunerated (Resolution N133 approved ..., 2017).

Deficiencies related to the weak control mechanisms used in the planning and execution process can be identified after the internal auditors have studied/analyzed the basics of each public procurement planning and implementation phase. It is also important that to adequately assess the processes, internal auditors use a variety of methods, interview/ survey, observation, and so on. These methods allow to correctly assessment the existing problem and its underlying causes.

As for changes in the timing of work performed without proper justification, it indicates the risks in the organization, especially since the penalty sanctions provided for in the contract are not applied. In addition to the risks listed above, it should also be noted that research/analysis should be done on corruption and fraud. Although confirming this is a rather difficult issue, the management of the organization should be informed about such risks to take effective steps on time by establishing control mechanisms and risk minimization.

Another issue covered by the State Procurement Report is the non-performance of all or part of the contracted works. This is a significant problem because of the inefficient management of budget funds. In addition to the evidence that may be obtained to confirm the performance of contracts, auditors need to verify the goods/services actually received. This will make it possible to assess the real state of the results obtained.

In terms of evaluating the internal control in budgetary institutions, we additionally analyzed the results of the audit conducted by the State Audit Office. Because in Georgia, it is the highest audit body, that carries out audits in public institutions by the annual plan. In 2019, the State Audit Office conducted 16 financial and 37 compliance audits. It is noteworthy that the audit reports present qualitatively and quantitatively inaccuracies, including issues related to internal control mechanisms (State Report of the ..., 2019). In particular, systemic shortcomings such as:

- Lack of detailed processes and procedures;

- Lack of IT and effective monitoring systems and / or malfunction; 
- Gaps in proper documentation of financial transactions and communication between structural units.

Across the country (Georgia), to evaluate the internal control system, we conducted additional qualitative research, in the framework of which an in-depth interview was conducted with the managers of the internal audit entities of the budgetary institutions. The interview focused on important issues such as the introduction of financial management and control, the assessment of the level of awareness related to internal control and the need to improve it, and more.

The study revealed several important circumstances, including:

1. The benefits of the internal control system are evaluated with an unequivocally high score;

2. Awareness in this area assessed as average at the management level and below-average at the employee level;

3. Some of the respondents mentioned that the introduction of financial management and control is in pilot mode, according to some of them, it has been introduced and is being refined, although a specific date of introduction could not be provided, while some of the respondents stated that the system is not implemented in the organization.

The above analysis and the results of our research confirm that the level of quality of internal control across the country is significantly low and it requires a systematic and effective approach.

The introduction and development of an internal control system in public institutions is important because the benefits it receives far outweigh the costs of implementing it. A mechanism ensures that not only the organization, but also the country achieves significant results, both in the short and long term. The benefits are manifested in the economic, productive, efficient, targeted, and rational spending of budget resources, in achieving the set goals and objectives, in the efficiency of risk management and control systems, and so on.

To determine and evaluate the benefits of the internal control system, we also considered it expedient to evaluate the real benefits of the internal audit entity (as a component of the internal control system) created in the budget institution, for which we studied and analyzed the results of internal audits.

A total of 107 findings were identified during the internal audit of the above-mentioned audit facility, of which the issues in terms of priority and highest risk content were distributed as follows:

- Public Procurement - Planning, Payment and Implementation;

Budget formation;

- Accounting and financial reporting;

Transfer of property to a third party;

It is important to note that as part of the audit carried out by the internal audit team, only the breaches in the cash ratio were as follows (see Figure 1 ).

It is also interesting to note that - the shortcomings identified in public procurement included both planning and. Implementation and settlement stages; The budget formation process was assessed as an imperfect, inefficient, and formal quality train; The financial statements were assessed as imperfect and unreliable, and the study of the transfer of property to a third party revealed a number of shortcomings, due to the lack of control mechanisms and the lack of qualifications of responsible employees.

It is also important to note here that the data presented by us in the sum indicator in the diagram does not fully reflect the result obtained as a result of the internal audit. As mentioned, several systemic deficiencies were identified during the audit, including those related to the internal control system, which did not have a direct financial impact on the organization at the time of the audit, although it puts its activities at high-risk.

Finally, the recommendations issued by the group of internal auditors concerned not only the elimination of specific deficiencies identified, but also the establishment of

Figure 1. The sum of the deficiencies identified by the internal audit at the stage of the audit 600000

\section{$505,419.29$}

400000

$327,880.00$

200000

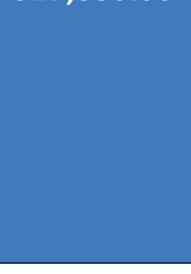

Budget formation

\section{$63,616.73$} reporting
$22,315.05$

ansfer of property to third party

Source: Budgetary Institution, 2017 Internal Audit Report 
an internal control system and the establishment of effective control mechanisms to minimize existing risks.

The above analysis, in addition to allowing us to assess the role and importance of internal audit, is also a good indicator in terms of evaluating the internal control system of the audited budget institution, given that the existing shortcomings indicate the inefficiency of the internal control system . Properly established, adequate, and effective control system is a prerequisite for the successful functioning of the organization through which. The set goals are achieved.

\section{The ways to solve the problem}

When we talk about the effectiveness of the internal control system and the problems associated with it, here we must consider ways to solve them. We believe that the most important and effective step in this regard is quality assurance (Public Sector ..., 2014).

To assess and analyze the relationship of problematic issues in terms of internal control with quality assurance issues, we also conducted a study of issues related to quality control of internal audit.

The "Internal Audit Methodology" in Georgia defines three main forms of quality control - internal evaluation, external evaluation, and ongoing supervision, and for each of them are defined ways of conduct, objectives, process, sample activities, organization issues, and others. It is also important to define the methods in which the internal audit entity can analyze the usefulness and effectiveness of the internal audit (Resolution N593 of ..., 2018).

During our qualitative research phase (which involved the managers of the internal audit entities of the budget sector), it was revealed that there are quality control tools in practice today, such as:

- Review of the final report and recommendation by the head of the internal audit entity;

- Monitoring individual audit / assignment;

- Involvement of the internal audit activity and submission of opinions after the completion of each inspection (Models of effective ..., 2015);

- Identify and self-assess internal audit risks at the annual planning stage.

It is also important to note that significant steps have been taken across the country in terms of quality improvement. External quality assessments were carried out in several ministries, during which all stages of the internal audit activity were evaluated. It covered issues such: establishment, management of audit activities, individual audit approaches, reporting and monitoring the implementation of the recommendation, issues of assured quality assurance, and more. According to the findings, relevant recommendations were issued by experts .

It should be noted that external quality assessment is currently underway at the municipal level, which in turn can be considered a positive factor.
Despite the steps taken forward, there are several problematic issues identified during the research phase and the resolution of which is a crucial issue for the development of internal audit. In particular:

- The current legislation of Georgia, which is guided by internal auditors, needs to be refined, improved, and updated.

- Most of the auditees participating in the study have not developed a unified / formal approach to the implementation of internal quality control, the existing quality control mechanisms are not documented and included in the unified system;

- In most cases, there is no relevant documentary evidence of internal quality control;

- There are cases when the independence of the internal audit entity is questioned because there are no appropriate and adequate protection measures;

- There is no internal audit committee that would play an important role in improving the independence and quality of internal auditors;

- Mandatory certification of internal auditors has not been introduced, which in turn would have a positive impact on auditors' qualifications and, consequently, quality;

- Only in a few cases is there a quality assurance and improvement program, which in turn affects the effective functioning of internal audit.

\section{Recommendations}

To improve the internal control methods and methodology in Georgia, we think that the following recommendations should be taken into account:

Introduction of internal control system - the development needs to develop and introduce common standards. Besides, best practices should be shared, training and workshops should be organized periodically, where representatives of the budget institution will be involved;

It is important to promote the development of internal audit as an internal control mechanism, which includes access to updated methodologies, guidelines, and standards, training. Certification, etc;

It is advisable to promote the introduction of internal audit quality assessment, which is reflected in the development of a unified methodology, sharing of experience gained, training of managers and auditors of the internal audit entity, development of internal standards, etc.;

It is important to promote the establishment of an effective internal control system, which includes the establishment and development of a structured system by international standards and current legislation, as well as its quality control.

\section{CONCLUSION}

As the results of our research and analysis have shown, despite the steps taken to implement and develop the internal control system, there are some problematic issues in our country regarding the improvement of the 
internal control system and quality control, which requires a systematic approach to be timely and effective. Their solution. We think that the recommendations developed by us will help to solve the existing problems and will have a positive impact on the full establishment of internal control in the budget sector.

\section{REFERENCES:}

2018 Consolidated Annual Report on the Development of State Internal Financial Control System, (2019).

International Standards on Internal Audit Practice, (2011). (Accessed 8 August 2017). https://global.theiia.org/translations/ PublicDocuments/Standards_2011_Georgian.pdf

Law of Georgia on State Internal Financial Control, (2010). https://matsne.gov.ge/ka/document/view/91618?publication=11 Measuring the Effectiveness of the Internal Audit Function, the Institute of Internal Auditors Netherlands. (2016).

Models of effective internal audit, Vahrtered Institute of Internal Auditors. (2015).

Order 11 / N of the Minister of Education, Science, Culture and Sports. (2019). - On Approval of the Statute of the Internal Audit Department of the Ministry of Education, Science, Culture and Sports of Georgia"; https://matsne.gov.ge/ka/document/ view/4472158?publication=1 (Accessed 7 Febraury 2019).

Order 644 of the Minister of Finance of Georgia of December 30, 2011 - On the Approval of the Risk Management Guidelines in the Public Sector. (Accessed 14 March 2016). https://matsne.gov.ge/ka/document/view/1546971?publication=0

Order 801 of the Minister of Finance of Georgia. (2010) - On Approval of the Statute of the Internal Audit Department; (ccessed 25 October 2017). https://matsne.gov.ge/ka/document/view/1060232?publication=9.

Order 89 / N of the Minister of Education, Science, Culture and Sports. (2012). - On Approval of the Statute of the Internal Audit Department of the Ministry of Education and Science of Georgia; (Accessed 8 May 2012). Retrieved from: https:// matsne.gov.ge/ka/document/view/1647920?publication=6

Public Sector Financial Management Reform Strategy and Action Plans for 2014-2017. https://mof.ge/images/File/ strategia/2014-2017_strategiis_document.pdf

Report of the State Audit Office on Audits Carried Out in 2014-2015 on the Expenditure and Execution of Municipal Budgets, (2016). https://sao.ge/Uploads/2019/11/adgilobrivi-2014-2015.pdf

Resolution 11 of the City Council of Akhaltsikhe Municipality. (2018) - On the approval of the Statute of the Internal Audit and Inspection Service of the City Hall of Akhaltsikhe Municipality; (Accessed 6 January 2019). https://matsne.gov.ge/ka/ document/view/4000427?publication=0

Resolution 133 approved by the Government of Georgia. (2017). - On Approval of the Instruction on the Rules and Procedures for Establishing the Financial Management and Control System; https://matsne.gov.ge/ka/document/ view/3613890?publication $=0$

Resolution 593 of the Government of Georgia. (2016). On Approval of the Internal Audit Methodology; (Accessed 1 April 2018). https://matsne.gov.ge/ka/document/view/3509521?publication=0

State Audit Compliance, Financial and Performance Audit Reports for 2015-2019 and 2016-2020; (Accessed 24 January 2020 ). State Report of the State Audit Office of Georgia. (2019). https://sao.ge/ka/about-us/Annual-Reports

Udesiani, T. (2015). Problematic issues related to internal audit in the public sector. Journal Accounting, 8, 7-15. (In Georgian). 